\title{
New phosphine-diamine and phosphine-amino- alcohol tridentate ligands for ruthenium catalysed enantioselective hydrogenation of ketones and a concise lactone synthesis enabled by asymmetric reduction of cyano-ketones
}

\author{
José A Fuentes, Scott D Phillips and Matthew L Clarke
}

\begin{abstract}
Enantioselective hydrogenation of ketones is a key reaction in organic chemistry. In the past, we have attempted to deal with some unsolved challenges in this arena by introducing chiral tridentate phosphine-diamine/Ru catalysts. New catalysts and new applications are presented here, including the synthesis of phosphine-amino-alcohol P,, $\mathrm{OH}$ ligands derived from (R,S)-1-amino-2-indanol, $(S, S)$-1-amino-2-indanol and a new chiral $P, N, N$ ligand derived from $(R$, $R)-1,2-$ diphenylethylenediamine. Ruthenium pre-catalysts of type $\left[\mathrm{RuCl}_{2}(\mathrm{~L})(\mathrm{DMSO})\right]$ were isolated and then examined in the hydrogenation of ketones. While the new $P, N, O H$ ligand based catalysts are poor, the new $P, N, N$ system gives up to $98 \%$ e.e. on substrates that do not react at all with most catalysts. A preliminary attempt at realising a new delta lactone synthesis by organocatalytic Michael addition between acetophenone and acrylonitrile, followed by asymmetric hydrogenation of the nitrile functionalised ketone is challenging in part due to the Michael addition chemistry, but also since Noyori pressure hydrogenation catalysts gave massively reduced reactivity relative to their performance for other acetophenone derivatives. The Ru phosphine-diamine system allowed quantitative conversion and around 50\% e.e. The product can be converted into a delta lactone by treatment with $\mathrm{KOH}$ with complete retention of enantiomeric excess. This approach potentially offers access to this class of chiral molecules in three steps from the extremely cheap building blocks acrylonitrile and methyl-ketones; we encourage researchers to improve on our efforts in this potentially useful but currently flawed process.
\end{abstract}

Keywords: Hydrogenation, Homogeneous catalysis, Keto-nitriles, P,N,O ligands, P,N,N ligands, Asymmetric synthesis, Chiral alcohols, Organocatalysis, Michael addition, Acrylonitrile

\section{Findings}

Reduction of $\mathrm{C}=\mathrm{O}$ and $\mathrm{C}=\mathrm{N}$ double bonds using molecular hydrogen is a very important process, due to its low cost and complete atom efficiency [1]. Homogeneous hydrogenation of unfunctionalised ketones could not be carried out with sufficient efficiency or chemoselectivity until the Noyori group's pioneering research on ruthenium complexes containing both diphosphine and diamine ligands (e.g. 1 and $\mathbf{2}$, Scheme 1) $[2,3]$. These catalysts give excellent results in the hydrogenation of a

\footnotetext{
* Correspondence: mc28@st-andrews.ac.uk

School of Chemistry, University of St Andrews, EaStCHEM, St Andrews, Fife KY16 9ST, UK
}

range of acetophenone derivatives, as have a number of structurally related catalysts $[4,5]$. However, $\left[\mathrm{RuCl}_{2}\right.$ (BINAP)(DAIPEN)] and related catalysts do have some important limitations, that have spurred significant interest in new catalyst development [6-21]. Given that so many drugs, agrochemicals, materials, and natural products can be disconnected back to enantiopure secondary alcohols, it is of significant importance to extend asymmetric hydrogenation chemistry such that it is effective for every major class of substrate. We have already reported on the reduction of some of these challenging substrates, namely bulky ketones [6,10,11], heterocycle appended (bulky) ketones [10], and certain esters [9]. To achieve 

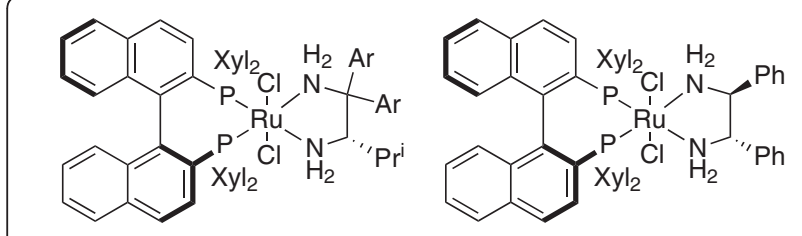

$\left[\mathrm{RuCl}_{2}(\mathrm{Xyl}-\mathrm{BINAP})(\mathrm{DAIPEN})\right]$ [RuCl$\left.((\mathrm{S})-\mathrm{BINAP})((\mathrm{S}, \mathrm{S})-\mathrm{DPEN})\right]$

1

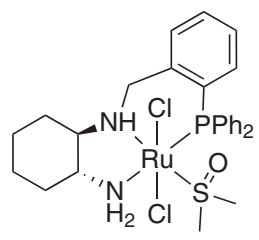

3

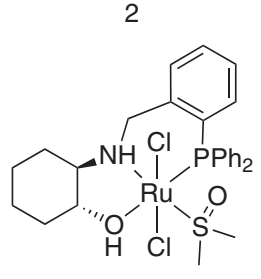

4

Scheme 1 Hydrogenation catalysts.

this, we developed ruthenium complexes of chiral tridentate $P, N, N$ and $P, N, O H$ ligands (derived from cyclohexane diamine and aminocyclohexanol). These gave moderate to excellent enantioselectivity and high yields where there was a precedent for $\left[\mathrm{RuCl}_{2}\right.$ (BINAP)(DAIPEN)] giving very low yields. However, while these results are significant in developing $P, N, N$ ligands for catalytic hydrogenation reactions, further improvements are needed for the catalysts to become industrially useful. In this paper, we report investigations into some alternative chiral backbones along with our initial attempt to apply these in a potentially concise asymmetric synthesis of delta lactones.

The original catalyst design presumed the primary amine terminus of the catalyst would bind ketones and activate hydrogen in the same manner as Noyori catalysts. However, our recent mechanistic studies showed that the secondary amine of catalyst $\mathbf{3}$ is influential in both the efficient activation of hydrogen, and (most likely) the control of selectivity in asymmetric hydrogenation [12]. Since the primary amine terminus in complex $\mathbf{3}$ seemed less important, we have reported a single example of a $P, N, O$ ligand and its $\mathrm{Ru}$ complex, $\mathbf{4}$ that gave good results in the enantioselective hydrogenation of ketones [12] and good activity in the hydrogenation of aromatic esters [9]. An important extension was to investigate a different chiral backbone that had a strong heritage in asymmetric catalysis, 1-amino-2-indanol.

Both diastereomers of the phosphine-amino-alcohol ligands $\mathbf{5}$ and $\mathbf{6}$ were readily prepared by condensation with diphenylphosphino-benzaldehyde followed by reduction with $\mathrm{NaBH}_{4}$ with unoptimised yields of 75-97\%. Reaction of phosphine-amino-alcohol ligands with $\left[\mathrm{RuCl}_{2}(\mathrm{DMSO})_{4}\right]$ gave, after purification, the diastereomeric complexes of formula $\left[\mathrm{RuCl}_{2}(\mathrm{PNOH})(\mathrm{DMSO})\right], \mathbf{5}$ and $\mathbf{6}$ in unoptimised yields of $67-78 \%$ (Scheme 2 ).

With the new $P, N, O H$ ligands in hand, we turned our attention to a new $P, N, N$ system. There are of course many diamines known in the literature that might be used to make new derivatives of these catalysts. It was envisaged that through modification of the diamine component, the orientation of the mechanistically important $\mathrm{N}-\mathrm{H}$ bond could be optimised to maximise catalyst activity and selectivity. Our previous research pointed towards tridentate ligands with relatively small $\mathrm{N}-\mathrm{N}$ angles being most suitable and this prompted us to focus on a $(R, R)-(+)-1,2$-diphenylethylenediamine derived ligand. It is worth noting that the synthesis of ligands with a primary amine terminus often proves more difficult than the phosphine-amino-alcohol systems, or for that matter, most phosphine ligands. The synthesis of the 'DPEN'derived ligand threw up several synthetic difficulties preventing the isolation of pure ligand, but the crude ligand was converted into its Ru complex that was then purified using column chromatography and fully characterised (Scheme 3). This could then be compared with the parent catalyst 3. On one occasion, this gave a $62 \%$ yield of complex 8, with no purification of the crude ligand, but a
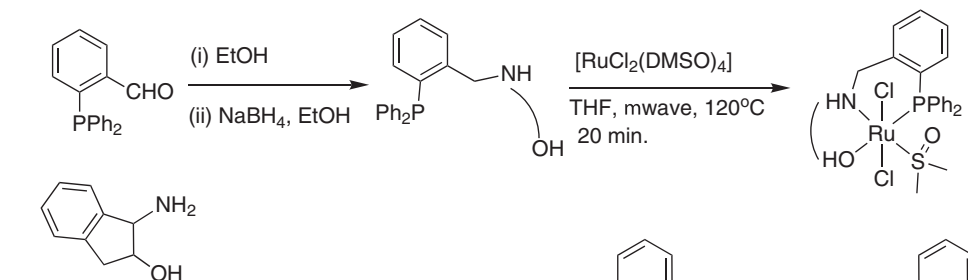

$(1 \mathrm{~S}, 2 \mathrm{R}),(1 \mathrm{~S}, 2 \mathrm{~S}) \&(1 \mathrm{R}, 2 \mathrm{~S})$ isomers

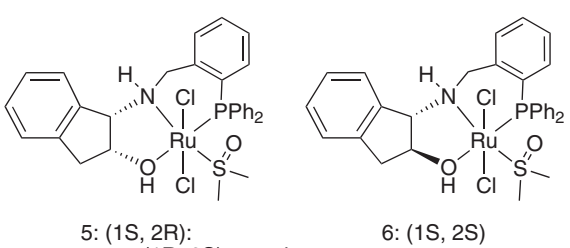

Scheme 2 Synthesis of $P, N, O H$ ligands and their $\mathrm{Ru}(\mathrm{II})$ complexes. 


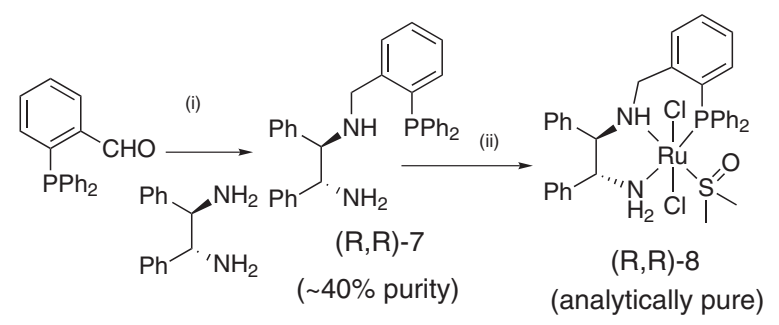

Scheme 3 Synthesis of DPEN-derived catalyst $(R, R)-8$. General conditions: (i) $(R, R)-(+)-1,2-$ diphenylethylenediamine (3 eq.), EtOH, $45^{\circ} \mathrm{C} \rightarrow \mathrm{rt}, 2 \mathrm{~h} ; \mathrm{NaBH}_{4}$ (4 eq.), EtOH, rt, 8 h; (ii) $(R, R)-7$ (1 eq.), $\left[\mathrm{RuCl}_{2}\right.$ $\left.(\mathrm{DMSO})_{4}\right]$ (1 eq.), $\mathrm{THF}, \mu \mathrm{w}, 120^{\circ} \mathrm{C}, 20 \mathrm{~min}$.

more reproducible method to generate pure material was to semi-purify the ligand using column chromatography although this gave lower yields. In any case, our objective was to test a pure catalyst of this type and this route was sufficient to achieve that.

Asymmetric hydrogenation of ketones, 9a-12a (Scheme 4) was attempted using $\mathbf{5}$, ent-5 and $\mathbf{6}$ as the catalyst. Modest enantioselectivities were obtained in the hydrogenation of the easy substrate acetophenone, 9a (Table 1, Entries 1-5). In contrast to the $P, N, N$ systems, enantioselectivity improves as base/Ru is increased up to $10: 1$, although even in the best scenarios, only $51 \%$ e.e. for alcohol $9 \mathrm{~b}$ could be realised. The catalyst did not have enough activity to reduce the poorly reactive ketone, 10a (Table 1, Entry 7). For comparison, some results using previously reported catalyst $\mathbf{4}$ are given. These show the hugely enhanced reactivity and selectivity with the bulky ketone 10a using catalyst 4, but we also highlight an issue of maintaining enantioselectivity when reducing catalyst loadings below $0.1 \%$.

Table 2 reports the results for a small section of substrates that were hydrogenated with catalyst $\mathbf{8}$.

Catalyst $\mathbf{8}$ was found to hydrogenate ketones quantitatively after 16 hours at $50^{\circ} \mathrm{C}$ and 50 bar hydrogen pressure (Table 3). Phenethyl alcohol was produced as practically racemic material as is generally the case with catalyst 3. The pressure hydrogenation of ketones with two alkyl carbons adjacent to the carbonyl has never given good results using any catalyst, so substrate 11a was attempted as a model for this, but no selectivity was observed. Reduction of $\alpha, \alpha$-dimethylpropiophenone 10a gave alcohol product in slightly increased enantioselectivity (80\% e.e. Table 2, Entry 2 ) relative to catalyst 3. Reactions run at lower catalyst loading and shorter times reveal that, for this substrate, the activity is similar for both 3 and 8. The reduced selectivity below $S / C=200$ is also a drawback sometimes observed with catalyst 3 ; this behaviour will most likely preclude large scale applications in asymmetric catalysis until a solution is found. Ketone 12a, deactivated by two bulky substituents and a

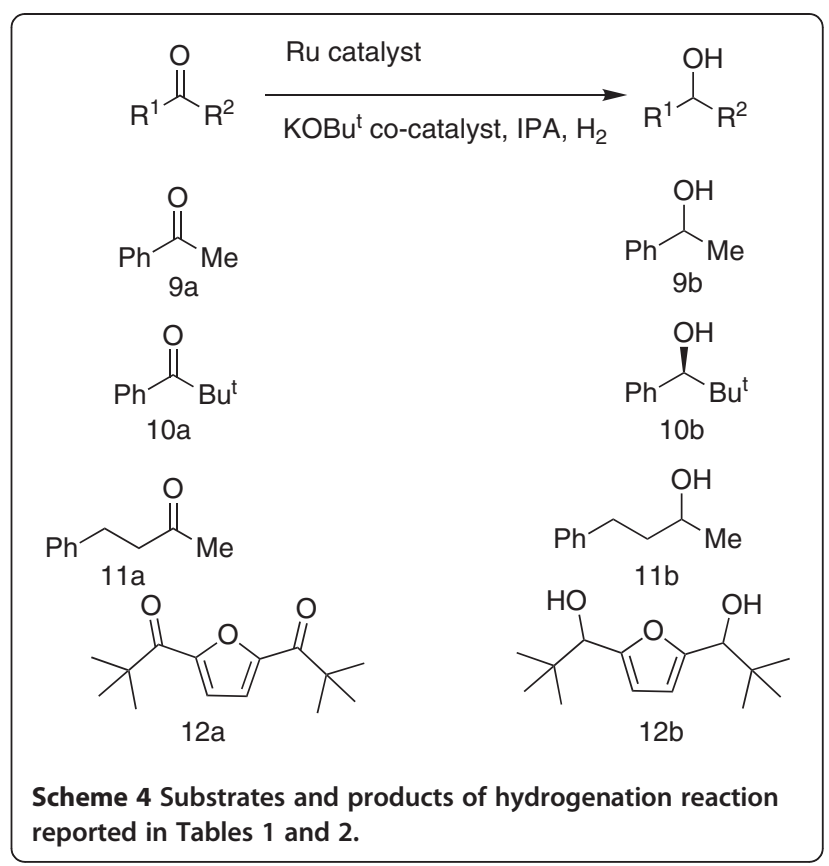

heterocycle gives a chiral diol, with potential as a chiral ligand, or as a precursor to chiral ligands. Hydrogenation of $\mathbf{1 2 a}$ with either catalyst $\mathbf{3}$ or $\mathbf{8}$ furnished the diol product in almost complete enantiopurity (the e.e. is amplified compared to that expected for the hydrogenation of a single carbonyl bond due the Horeau effect, whereby the formation of meso compound allows for the 'removal' of the undesired enantiomer [22]. This initial screen was sufficient to confirm that $\mathbf{8}$ is a competent alternative to catalyst $\mathbf{3}$, although so far with no advantages, especially given its difficult synthesis.

A particular interest in our research group is seeking to use catalytic methods to promote the synthesis of high-value-added functionalised molecules from bulk and commodity chemicals with maximum atom-efficiency. With this concept in mind, a rather narrow range of reaction types can be used to keep to these principles $[23,24]$, but Michael addition and hydrogenation fit this criteria. A general synthesis of enantiomerically enriched delta-lactones might be possible from the bulk chemical acrylonitrile and methyl ketones as shown in Scheme 5. $\delta$-lactones represent an important class of natural products with interesting applications in the flavour and fragrance industry in particular [25]. Their synthesis is generally quite labour intensive, although lactone $\mathbf{1 5}$ has previously been made by CBS reduction of a hydroxyester and ester hydrolysis-lactonisation [26]. Two of the key steps in our very concise synthesis represent quite underdeveloped chemistry. As far back as 1955, the organocatalytic Michael addition to acrylonitrile was reported in a patent [27], but no modern examples of organocatalytic acrylonitrile Michael additions exist. In 
Table 1 Enantioselective hydrogenation of some ketones using Ru catalysts derived from phosphine-aminoalcohols

\begin{tabular}{|c|c|c|c|c|c|c|}
\hline Entry $^{[a]}$ & Cat & Ketone & $\begin{array}{l}\text { [cat] } \\
\text { mol\% }\end{array}$ & $\begin{array}{l}\text { [base] } \\
\text { mol\% }\end{array}$ & $\begin{array}{l}\text { Conversion } \\
\text { (yield) [\%] }^{[\mathrm{b}]}\end{array}$ & $\begin{array}{l}\text { e.e. } \\
{[\%]^{[c]}}\end{array}$ \\
\hline 1 & 5 & $9 a$ & 0.5 & 1 & 99 & $23(S)$ \\
\hline 2 & 6 & $9 a$ & 0.5 & 1 & 99 & $27(R)$ \\
\hline 3 & ent-5 & $9 a$ & 0.5 & 1 & 99 & $29(R)$ \\
\hline 4 & ent-5 & $9 a$ & 0.5 & 2.5 & 99 & $43(R)$ \\
\hline 5 & ent-5 & $9 a$ & 0.5 & 5 & 98 & $51(R)$ \\
\hline 6 & 4 & $9 a$ & 0.5 & 2.5 & 99 (99) & $15(S)$ \\
\hline 7 & 5 & $10 a$ & 0.5 & 1 & 26 & 4 \\
\hline 8 & 4 & $10 a$ & 0.5 & 2.5 & $99(99)$ & $74(S)$ \\
\hline $9^{[d]}$ & 4 & $10 a$ & 0.5 & 2.5 & 99 & $79(S)$ \\
\hline $10^{[e]}$ & 4 & $10 a$ & 1 & 5 & 98 & $80(S)$ \\
\hline 11 & 4 & $10 a$ & 0.09 & 5 & 45 & $3(S)$ \\
\hline 12 & 6 & $11 a$ & 0.5 & 2.5 & 99 (97) & 0 \\
\hline
\end{tabular}

[a] Unless otherwise indicated, reactions were carried out using $0.33 \mathrm{mmol} \mathrm{mL}^{-1}$ of ketone at $50^{\circ} \mathrm{C}$ and $50 \mathrm{bar}$ of hydrogen pressure with a $16 \mathrm{~h}$ reaction time using $t$-BuOK as base. ${ }^{[b]}$ Conversions were determined by ${ }^{1} \mathrm{H}$ NMR analysis of the crude reaction mixtures (all peaks were assigned). Yields are for pure alcohols after short-path silica gel chromatography. ${ }^{[c]}$ The e.e. value was determined by chiral HPLC. ${ }^{[d]} 35^{\circ} \mathrm{C}$. ${ }^{[e]} 3 \mathrm{~h}$.

our hands, this reaction only gave $30 \%$ yield of the desired ketone (and a brief screen of some other primary and secondary amines did not improve this). Whilst this substrate can be accessed by other routes in higher yield (see Additional file 1 and ref [28]), the organocatalytic Michael addition approach is worthy of a further research study given its atom-efficiency, its use of very simple, cheap reagents and the potential utility of the products. To the best of our knowledge, the asymmetric hydrogenation of nitrile-functionalised ketones does not appear in any of the plethora of

Table 2 Enantioselective hydrogenation of some ketones using catalyst 8

\begin{tabular}{lccccc}
\hline Entry $^{\boldsymbol{a}}$ & Ketone & Catalyst & Time (h) & Conversion [\%] & e.e. [\%] \\
\hline 1 & $\mathbf{9 a}$ & $(R, R)-8(0.5 \%)$ & 16 & $>99$ & 3 \\
2 & $\mathbf{1 0 a}$ & $(R, R)-8(0.5 \%)$ & 16 & $>99$ & $80(S)$ \\
3 & $\mathbf{1 0 a}$ & $(R, R)-3(0.5 \%)$ & 16 & $>99$ & $74(S)$ \\
4 & $\mathbf{1 0 a}$ & $(R, R)-8(0.33 \%)$ & 1 & 44 & $56(S)$ \\
5 & $\mathbf{1 0 a}$ & $(S, S)-3(0.33 \%)$ & 1 & 45 & $65(R)$ \\
6 & $\mathbf{1 1 a}$ & $(R, R)-8$ & 16 & $>99$ & 9 \\
7 & $\mathbf{1 2 a}$ & $(R, R)-8$ & 16 & $>99$ & $98^{\mathrm{d}}$ \\
$8^{\mathrm{e}}$ & $\mathbf{1 2 a}$ & $(R, R)-3$ & 16 & $>99$ & $98^{\mathrm{f}}$ \\
\hline
\end{tabular}

${ }^{a}$ Reactions were carried out using $0.33 \mathrm{mmol} \mathrm{mL}^{-1}$ of ketone, $0.5 \mathrm{~mol} \%$ preformed catalyst $(R, R)-\mathbf{2 7}$ and $1 \mathrm{~mol} \% \mathrm{KO}^{t} \mathrm{Bu}$ at $70^{\circ} \mathrm{C}$ and 50 bar of hydrogen pressure with a $16 \mathrm{~h}$ reaction time. ${ }^{b}$ Conversions were determined by ${ }^{1} \mathrm{H}$ NMR analysis of the crude reaction mixtures (all peaks assigned). ${ }^{c}$ The e.e. value was determined by chiral HPLC (Chiralpak AD-H/Chiralcel OD-H column). The absolute configuration was determined to be $S$ by comparison of optical rotation values with literature values. ${ }^{\mathrm{d}}((R, R)+(S, S))$ :meso 3.1:1. ${ }^{\mathrm{e}}$ Reaction temperature of $50^{\circ} \mathrm{C}$. $\{(R, R)+(S, S)\}:$ meso $2.8: 1$.
Table 3 Enantioselective hydrogenation of ketone 13

\begin{tabular}{|c|c|c|c|c|}
\hline Entry $^{a}$ & Catalyst & Temp. $\left({ }^{\circ} \mathrm{C}\right)$ & Conversion (\%) & e.e. $(\%)^{c}$ \\
\hline 1 & 2 & 70 & $21^{d}$ & 56 \\
\hline 2 & 3 & 70 & $>99$ & 49 \\
\hline 3 & 8 & 70 & 37 & 50 \\
\hline 4 & 3 & 50 & 14 & 54 \\
\hline 5 & 4 & 70 & $<5$ & n.d. \\
\hline \multicolumn{5}{|c|}{$\begin{array}{l}{ }^{a} \text { Reactions were carried out using } 0.5 \mathrm{~mol} \% \text { preformed catalyst and } 1 \mathrm{~mol} \% \\
\mathrm{KO} \mathrm{K}^{t} \mathrm{Bu} \text { at } 70^{\circ} \mathrm{C} \text { and } 50 \text { bar of hydrogen pressure with a } 16 \mathrm{~h} \text { reaction time } \\
\text { unless indicated otherwise. }{ }^{b} \text { Conversions were determined by }{ }^{1} \mathrm{H} \text { NMR } \\
\text { analysis of the crude reaction mixtures (all peaks assigned). }{ }^{c} \text { The e.e. value } \\
\text { was determined by chiral HPLC (Chiralpak AD-H/Chiralcel OD-H column). The } \\
\text { absolute configuration was determined to be } S \text { by comparison of optical } \\
\text { rotation values with literature values. }{ }^{d} \text { Base: catalyst of } 50: 1 \text { used as is more } \\
\text { common with Noyori catalysts. }\end{array}$} \\
\hline
\end{tabular}

publications on ketone hydrogenation, although there are reports of transfer hydrogenation of $\alpha$-cyano-ketones [29]. There are probably two reasons for this gap in literature; $\mathrm{Ru}$ complexes would be envisaged to hydrogenate the nitrile [30], but also as we report in Scheme 5<smiles>[R]C(=O)C(=O)CCCC#N</smiles> 
and Table 3, this type of substrate seems to inhibit typical hydrogenation catalysts.

The asymmetric hydrogenation of the keto-nitrile $\mathbf{1 3}$ was studied using conditions that will readily reduce simple acetophenones. We found that the Noyori catalyst, 2 only gave a $21 \%$ conversion to product at $70^{\circ} \mathrm{C}$ with $56 \%$ e.e. (Table 3, Entry 1). On the other hand, catalyst 3 gave quantitative conversion to the desired alcohol, with complete chemoselectivity and a moderate $49 \%$ e.e. (Table 3, Entry 2). Lowering the temperature or switching to catalyst 8 resulted in lower conversion and no significant increases in enantioselectivity (Table 3, Entries 3-5). The $P, N, O H$ catalyst, $\mathbf{4}$ was inactive. It is clear that the nitrile-ketones are extremely challenging substrates, although the St Andrews catalysts show distinct promise for this little studied but potentially useful class of ketone hydrogenations. We firmly encourage other researchers to improve on our efforts. The chiral alcohol produced was treated with $\mathrm{KOH}$ at high temperature resulting in formation of the lactone $\mathbf{1 5}$ in $62 \%$ yield. HPLC analysis and comparison of optical rotation data shows that this occurred with complete retention of stereochemistry. We briefly examined a gem-dimethyl analogue of $\mathbf{1 3}$ using catalyst 3 and were pleased to find it gave quantitative conversion and $74 \%$ e.e. for the product 17 , and that this could also be converted into lactone $\mathbf{1 8}$ with complete retention of stereochemistry.

\section{Conclusions}

The important objective of comparing a different phosphine-amino-alcohol ligand to catalyst $\mathbf{4}$ has been accomplished, although this has ultimately delivered poor catalysts. The $(R, R)-1,2$-diphenylethylenediamine derived catalyst, while not offering large advantages over the previous systems developed in our laboratory is quite an effective catalyst that we now use in catalyst screening for more application-orientated studies. An example of a rather unique, but not yet viable, application of these catalysts is the delta lactone synthesis described; this potentially offers access to this class of molecules in three steps from the extremely cheap building blocks acrylonitrile and methyl-ketones. Both the organocatalytic acrylonitrile Michael addition and the asymmetric hydrogenation of nitrile-functionalised ketones are interesting unresolved target applications to spur the evaluation of new catalysts.

\section{Additional file}

Addition file 1: Full experimental details are available in Additional file 1.

\section{Competing interests}

The authors declare they have no competing interests.

\section{Authors' contributions}

MC conceived of the projects described herein, assisted with experimental design and wrote the paper. SP carried out most of the 'DPEN' catalyst studies and the lactone synthesis. JF carried out the studies on the PNOH catalysts, prepared some substrates, contributed towards the synthetic studies on the DPEN catalyst and assisted in the writing of the paper. All authors read and approved the final manuscript.

\section{Authors' information}

Matt Clarke leads a research group that is developing greener scaleable catalytic synthetic methods at the University of St Andrews, EaStCHEM. The group works closely with industry. While the results of the groups work have been published in around 65 recent articles in the leading international chemistry journals, the authors are keen supporters of open-access journals that offer either free publication and access, or an institutional membership. Dr Scott Phillips completed his PhD in the Clarke group in 2011, specialising in asymmetric hydrogenation using Ru complexes of tridentate ligands. Dr José Fuentes completed his PhD in 2004 and is a post-doctoral research fellow and honorary lecturer in the Clarke group who is currently involved in several projects ranging from using supramolecular co-catalysts to optimise homogeneous catalytic reactions, the simultaneous control of regioselectivity and enantioselectivity in various alkene carbonylations and asymmetric hydrogenation reactions.

\section{Acknowledgements}

The authors thank all the technical staff at the University of St Andrews School of Chemistry for their efforts. This research was funded by the EPSRC.

Received: 6 November 2012 Accepted: 4 December 2012 Published: 10 December 2012

\section{References}

1. De Vries JG, Elsevier CJ: Handbook of homogeneous hydrogenation. Wiley VCH: Weinheim; 2007.

2. Noyori R, Ohkuma T: Asymmetric catalysis by architectural and functional molecular engineering: practical chemo- and stereoselective hydrogenation of ketones. Angew Chem Int Ed 2001, 40:40-73.

3. Ohkuma T, Ooka H, Hashiguchi S, Ikariya T, Noyori R: Practical enantioselective hydrogenation of aromatic ketones. J Am Chem Soc 1995, 117:2675-2676.

4. Ohkuma T, Sandoval CA, Srinivasan R, Lin Q, Wei Y, Muniz K, Noyori R: Asymmetric hydrogenation of tert-alkyl ketones. J Am Chem Soc 2005, 127:8288-8289.

5. Burk MJ, Hems W, Herzberg D, Malan C, Zanotti-Gerosa A: A catalyst for efficient and highly enantioselective hydrogenation of aromatic, heteroaromatic, and alpha, beta-unsaturated ketones. Org Lett 2000 2:4173-4176.

6. Clarke ML, Diaz-Valenzuela MB, Slawin AMZ: Hydrogenation of aldehydes, esters, imines, and ketones catalyzed by a ruthenium complex of a chiral tridentate ligand. Organometallics 2007, 26:16-19.

7. Abdur-Rashid K, Guo RW, Lough AJ, Morris RH, Song DT: Synthesis of ruthenium hydride complexes containing beta-aminophosphine ligands derived from amino acids and their use in the $\mathrm{H} 2$-hydrogenation of ketones and imines. Adv Synth Catal 2005, 347:571-579.

8. Baratta W, Ballico M, Chelucci G, Siega K, Rigo P: Osmium(II) CNN pincer complexes as efficient catalysts for both asymmetric transfer and $\mathrm{H}(2)$ hydrogenation of ketones. Angew Chem Int Ed 2008, 47:4362-4365.

9. Carpenter I, Eckelmann SC, Kuntz MT, Fuentes JA, France MB, Clarke ML: Convenient and improved protocols for the hydrogenation of esters using Ru catalysts derived from $(\mathrm{P}, \mathrm{P}),(\mathrm{P}, \mathrm{N}, \mathrm{N})$ and $(\mathrm{P}, \mathrm{N}, \mathrm{O})$ ligands. Dalton Trans 2012, 41:10136-10140.

10. Diaz-Valenzuela MB, Phillips SD, France MB, Gunn ME, Clarke ML Enantioselective hydrogenation and transfer hydrogenation of bulky ketones catalysed by a ruthenium complex of a chiral tridentate ligand. Chem-Eur J 2009, 15:1227-1232.

11. Phillips SD, Andersson KHO, Kann N, Kuntz MT, France MB, Wawrzyniak P, Clarke ML: Exploring the role of phosphorus substituents on the enantioselectivity of Ru-catalysed ketone hydrogenation using tridentate phosphine-diamine ligands. Catal Sci Technol 2011, 1:1336-1339.

12. Phillips SD, Fuentes JA, Clarke ML: On the NH effect in rutheniumcatalysed hydrogenation of ketones: Rational design of phosphine- 
amino-alcohol ligands for asymmetric hydrogenation of ketones. Chem-Eur J 2010, 16:8002-8005.

13. Ito J, Ujiie S, Nishiyama H: New bis(oxazolinyl)phenyl-ruthenium(II) complexes and their catalytic activity for enantioselective hydrogenation and transfer hydrogenation of ketones. Organometallics 2009, 28:630-638.

14. Ito $\mathrm{M}$, Endo $\mathrm{Y}$, Ikariya $\mathrm{T}$ : Well-defined triflylamide-tethered arene-ru (tsdpen) complexes for catalytic asymmetric hydrogenation of ketones. Organometallics 2008, 27:6053-6055.

15. Jolley KE, Zanotti-Gerosa A, Hancock F, Dyke A, Grainger DM, Medlock JA, Nedden HG, Le Paih JJM, Roseblade SJ, Seger A, Sivakumar V, Prokes I, Morris DJ, Wills M: Application of tethered ruthenium catalysts to asymmetric hydrogenation of ketones, and the selective hydrogenation of aldehydes. Adv Synth Catal 2012, 354:2545-2555.

16. Naud F, Malan C, Spindler F, Ruggeberg C, Schmidt AT, Blaser HU: Ru(phosphine-oxazoline) complexes as effective, industrially viable catalysts for the enantioselective hydrogenation of aryl ketones. Adv Synth Catal 2006, 348:47-50.

17. WWN O, Lough AJ, Morris RH: The hydrogenation of molecules with polar bonds catalyzed by a ruthenium(II) complex bearing a chelating $\mathrm{N}$ heterocyclic carbene with a primary amine donor. Chem Commun 2010, 46:8240-8242.

18. Touge T, Hakamata T, Nara H, Kobayashi T, Sayo N, Saito T, Kayaki Y, Ikariya T: Oxo-tethered ruthenium(II) complex as a bifunctional catalyst for asymmetric transfer hydrogenation and $(\mathrm{H} 2)$ hydrogenation. J Am Chem Soc 2011, 133:14960-14963.

19. Ohkuma T, Utsumi N, Tsutsumi K, Murata K, Sandoval C, Noyori R: The hydrogenation/transfer hydrogenation network: asymmetric hydrogenation of ketones with chiral $n 6$-arene/ $\mathrm{N}$-tosylethylenediamine ruthenium(II) catalysts. J Am Chem Soc 2006, 128:8724-8725.

20. Wang C, Villa-Marcos B, Xiao JL: Hydrogenation of imino bonds with halfsandwich metal catalysts. Chem Commun 2011, 47:9773-9785.

21. Xu YJ, Alcock NW, Clarkson GJ, Docherty G, Woodward G, Wills M: Asymmetric hydrogenation of ketones using a ruthenium(II) catalyst containing binol-derived monodonor phosphorus-donor ligands. Org Lett 2004, 6:4105-4107.

22. Vigneron JP, Dhaehens M, Horeau A: Nouvelle methode pur porter au maximum la purete optique d'un produit partiellement dedouble sans I'aide d'aucune substance chirale. Tetrahedron 1973, 29:1055-1059.

23. Clarke ML, Roff GJ: Highly regioselective rhodium catalysed hydroformylation of unsaturated esters: the first practical method for quaternary selective carbonylation. Chem-Eur J 2006, 12:7978-7986.

24. Noonan GM, Cobley CJ, Lebl T, Clarke ML: Asymmetric hydroformylation of an enantiomerically pure bicyclic lactam; efficient synthesis of functionalised cyclopentylamines. Chem-Eur J 2010, 16:12788-12791.

25. Sabitha G, Bhaskar V, Yadav JS: The first asymmetric total synthesis of (R)-tuberolactone, (S)-jasmine lactone and (R)-delta-decalactone. Tetrahedron Lett 2006, 47:8179-8181.

26. Downham R, Edwards PJ, Entwistle DA, Hughes AB, Kim KS, Ley SV: Dispiroketals in synthesis 19. Dispiroketals as enantioselective and regioselective protective agents for symmetrical cyclic and acyclic polyols. Tetrahedron-Asymm 1995, 6:2403-2440.

27. Krimm H: Process for the production of a-monocyanoethyl ketones. US patent (Farbenfabrika Bayer Aktengesellshaft), US1958:2850519.

28. Wessig $\mathrm{P}$, Muehling $\mathrm{O}$ : Photochemical synthesis of highly functionalised cyclopropyl ketones. Helv chim Acta 2003, 86:865-885.

29. Soltani O, Ariger MA, Henar W, Carreira EM: Transfer Hydrogenation in water: enantioselective, catalytic reduction of alpha cyano and alpha nitro acetophenones. Org Lett 2010, 12:2893-2895.

30. Enthaler $S$, Junge $K$, Addis D, Erre G, Beller M: A practical and benign synthesis of primary amine through ruthenium-catalysed reduction of nitriles. Chemsus Chem 2008, 1:1006-1010.

\section{doi:10.1186/1752-153X-6-15}

Cite this article as: Fuentes et al: New phosphine-diamine and phosphine-amino-alcohol tridentate ligands for ruthenium catalysed enantioselective hydrogenation of ketones and a concise lactone synthesis enabled by asymmetric reduction of cyano-ketones. Chemistry Central Journal 2012 6:151.

Publish with ChemistryCentral and every
scientist can read your work free of charge
"Open access provides opportunities to our
colleagues in other parts of the globe, by allowing
anyone to view the content free of charge."
W. Jeffery Hurst, The Hershey Company.
- available free of charge to the entire scientific community
- peer reviewed and published immediately upon acceptance
- cited in PubMed and archived on PubMed Central
- yours - you keep the copyright
submit your manuscript here:
http://www.chemistrycentral.com/manuscript/

